\title{
DISCOUNT PRICING FOR RESIDENTS AND REGISTRARS
}

\author{
Henry R. Cowell \\ Frank Horan
}

Over the years, the Journal of Bone and Joint Surgery has served as a major educational tool and resource for individuals in training around the world. Recognising the need to make the Journal readily available to individuals in training, the Board of Trustees of the American volume of the Journal and the British Council of Management of the British volume of the Journal have jointly decided to reduce the price of both volumes for a three-year period for each individual in training. This reduction begins with new subscriptions and subscription renewals for 1999. Any resident or registrar who orders a new subscription, or renews a current subscription, for 1999 will receive a discount of $50 \%$. Thus, the price for the combined American and British volumes will be $\$ 77.50$ ( $£ 48.00$ ) rather than the regular price of $\$ 155.00$ ( $£ 97.00$ ); the price for the American volume alone will be $\$ 48.00$ ( $£ 30.00$ ) rather than the regular price of $\$ 96.00$ ( $£ 60.00)$, and that for the British volume alone will be $\$ 33.50$ (£21.00) rather than the regular price of $\$ 67.00$ ( $£ 42.00)$. A discount of $35 \%$ will be offered in the second subscription year and a discount of $20 \%$, in the third subscription year. Records will be kept at the subscription offices, and residents will be billed at the second- and third-year rates automatically. A request for a subscription at the reduced price must be accompanied by a letter from the Chief of Service noting that the individual

(C)1998 British Editorial Society of Bone and Joint Surgery 0301-620X/98/59366\$2.00

J Bone Joint Surg [Br] 1998;80-B:753. requesting the subscription is a resident or registrar in training.

Recognising that many individuals are interested in subscribing to the American and British volumes on CD-ROM, the price of the CD-ROM subscription produced by the American and British volumes has been decreased as well. The new price for residents for the combined CD-ROM, which contains full text and illustrations from 1996, 1997, and the first six months of 1998 and is updated quarterly, is $\$ 120.00$ for individuals in training. Again, a letter is required from the Chief of Service confirming that the individual is a resident or registrar. In line with these price decreases, the Board of Trustees of the American volume of the Journal and the British Council of Management have decided to decrease prices for the CD-ROM subscription across the board from $\$ 295.00$ to $\$ 150.00$ for subscribers to the Journal, from $\$ 375.00$ to $\$ 195.00$ for non-subscribers, and from $\$ 475.00$ to $\$ 395.00$ for CD-ROMs to be used on a network. The pricing of the archival CD-ROM of the American volume, which contains the full text and tables from 1983 through 1997 and the images from 1990 through 1997, will remain unchanged. Similarly, the price for the archival disk of the British volume, which contains the full text and tables from 1984 through 1992 and the images from 1993 through 1997, will remain unchanged.

The Board of Trustees of the American volume of the Journal and the British Council of Management are pleased that the continued financial health of both journals allows these reductions in the subscription price for individuals in training and for the CD-ROM subscription. 